\title{
La «cuestión criolla» en Zama, de Antonio Di Benedetto (1956) y Zama, el filme de Lucrecia Martel (2016)

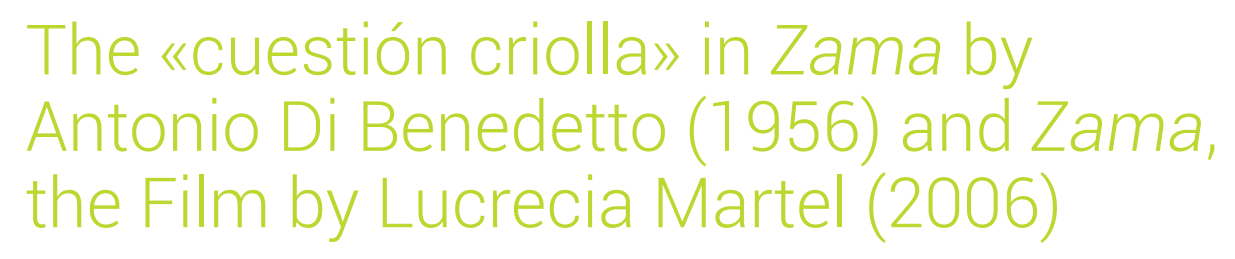

\section{Giovanna Pollarolo}

Pontificia Universidad Católica del Perú

PERÚ

gpollarolo@pucp.edu.pe

[Hipogrifo, (issn: 2328-1308), 7.2, 2019, pp. 247-268]

Recibido: 20-12-2018 / Aceptado: 30-01-2019

DOI: http://dx.doi.org/10.13035/H.2019.07.02.21

Resumen. Zama' ${ }^{1}$ y su adaptación al cine en el 2016 por Lucrecia Martel², relatan el drama de don Diego de Zama, asesor letrado del gobernador de una provincia periférica al norte del Virreinato del Río de la Plata. La novela ha sido leída como la alegoría de la condición existencial del ser humano y, por lo tanto, atemporal. Sin negar esta interpretación, propongo que, tanto la novela como la película, dramatizan la situación del criollo en la realidad colonial del siglo XVIII desde una perspectiva que da cuenta de la llamada «cuestión criolla». En el presente trabajo intento mostrar que tanto la novela como la película - pero esta aún con mayor énfasis-, mediante la simbolización propia de la ficción e inscribiéndose en un marco histórico y geográfico de fines del siglo XVIII, narran la situación de postergación del criollo en la estructura del poder colonial pocos años antes de las guerras independentistas.

1. Antonio Di Benedetto, Zama, Buenos Aires, Adriana Hidalgo editora, 2013 [1956]. Todas las citas serán por la edición de 2013.

2. Lucrecia Martel (directora), Zama, Daniel Giménez Cacho, Matheus Nachtergale, Juan Minujin, Lola Dueñas, Rafael Spregelburd, Coproducción Argentina-España-Francia-México-Brasil-Estados UnidosPaíses Bajos (Holanda), Rei Cine/El Deseo/Canana Films/KNM/Bananeira Filmes/Louverture Films/ Netherland Filmfund/INCAA, 2016. 
Palabras clave. «Cuestión criolla»; siglo XVIII; centro y periferia; «realidad histórica»; alegoría.

Abstract. Zama, and its adaptation to the cinema in 2016 by Lucrecia Martel, relates the drama of Don Diego de Zama, legal advisor to the governor of a peripheral province north of the Viceroyalty of Río de la Plata. The novel has been read as the allegory of the existential condition of the human being and, therefore, timeless. Without denying this interpretation, I propose that, both the novel and the film, dramatize the situation of «criollos» in the colonial reality of the eighteenth century from a perspective that accounts for the so-called «cuestión criolla». In the present work I try to show that both the novel and the film, but it is even more emphasized, through the symbolization of fiction itself and enrolling in a historical and geographical framework of the late eighteenth century, narrate the situation of postponement of the Creole in the structure of colonial power a few years before the independence wars.

Keywords. «Cuestión criolla»; Eighteenth Century; Center and Periphery, «Historical Reality»; Allegory.

Zama, la novela y la película, narran la vida solitaria y progresiva degradación de don Diego de Zama, asesor letrado en una gobernación marginal, nunca identificada, del virreinato del Río de la Plata. Funcionario nombrado por el rey, espera la carta que autorice su traslado a Buenos Aires o a Santiago de Chile. Dice Zama en la novela: «Perú seguía en la línea de mis aspiraciones; lo más codiciado, como culminación, España» ${ }^{3}$. «He pedido mi traslado a Lerma, España» ${ }^{4}$, dice en el filme. La espera de Diego de Zama ha sido entendida por gran parte de la crítica como una alegoría de la condición existencial del ser humano, aun cuando la trama remita al tiempo histórico colonial. Se considera, asimismo, que Zama, el libro, se aparta de las fórmulas de la llamada «novela histórica» (ausencia de grandes hechos de la historia oficial como marco de la trama; ausencia de precisiones geográficas). Sin embargo, y esta es mi propuesta, más allá de la alegoría, la condición de sujeto criollo de Diego de Zama es determinante en la novela y fundamental en la adaptación que realizó Lucrecia Martel en el 20165. En lo que sigue, indagaré en episodios de la novela y de la película que permitirán argumentar mi planteamiento. Pero antes de ello, expondré brevemente algunos de los acercamientos críticos a Zama,

3. Di Benedetto, Zama, p. 88

4. Martel, Zama

5. Entiendo, siguiendo a Robert Stam, la figura de la «adaptación como lectura», en inglés «adaptation as a Reading» (Stam, 2000, p. 62). Quien adapta, en este caso una novela, propone una lectura del texto, Ilamado «hipotexto» por Gerard Genette (Palimpsestos, 1989), al que refiere de manera explícita. Mediante una serie de operaciones textuales realizadas por los adaptadores, «selección, amplicación, concretización, actualización, crítica, extrapolación, analogía, popularización y re-culturización», en inglés «selection, amplification, concretization, actualization, critique, extrapolation, analogization, popularization, and reculturalization» (Stam, 2000, p. 68), el nuevo texto, llamado «hipertexto» en la nomenclatura de Genette, adquiere sentidos y significaciones que dan cuenta de su propuesta de lectura. 
la novela; y luego me referiré a la «cuestión criolla» desde la perspectiva propuesta por la historia colonial, presente en Zama y dimensionada en la película homónima.

\section{ZAMA: «OBJETO ESQUIVO»}

Zama, señala Del Vecchio, es un «Objeto esquivo, que resiste indemne cualquier intento de aprehensión taxonómica que pretenda abarcarlo» ${ }^{6}$. Y si bien «dialoga a través de sus estrategias, con distintos géneros (la novela existencial, la novela histórica, la nouveau roman, la epopeya americana, entre otros)» ${ }^{7}$, no pertenece a ninguno de ellos. Se trata, prosigue Del Vecchio, de una novela tan atípica como su autor, a quien se refiere como «excéntrico, geográfica y literariamente»: escribe en Mendoza, lejos de Buenos Aires y más lejos aún de Europa. En efecto, es posible trazar un paralelo entre la vida azarosa, doliente y en cierto modo marginal y descentrada de Antonio Di Benedetto y la de don Diego de Zama. Esta lectura proviene de los términos en los que se definió Di Benedetto en su «Autobiografía»: «Soy argentino, pero no he nacido en Buenos Aires» ${ }^{9}$, con lo cual remite a la Argentina como país dividido en dos: la capital y el resto, donde la primera es percibida como una ciudad europea, moderna, del primer mundo; en tanto que «el resto» es parte de esa América Latina marginal, siempre a la zaga de Europa. De allí el énfasis en las tensiones entre la provincia profunda y la civilización, entre la modernidad y lo tradicional, el centro y la periferia representados en la novela.

En el prólogo que escribió para la edición publicada por Clarín, Juan José Saer señala que, aunque Zama nos cuenta hechos transcurridos hace casi dos siglos, en realidad, «nos narra a nosotros, sus lectores» ${ }^{10}$. Y agrega: «Por ser la novela de la espera y de la soledad, no hace sino representar a su modo, oblicuamente, la condición profunda de América, que titila, frágil, en cada uno de nosotros. [...] La agonía oscura de Zama es solidaria de la del continente en el que esa agonía tiene lugar» ${ }^{11}$. En esta línea, Ximena Néspolo entiende que «Desarraigado de su entorno, a la espera de un ascenso que nunca llega, el drama del funcionario Diego de Zama se proyecta desde el siglo XVIII a nuestro presente con inusitada fuerza» ${ }^{12}$ dando cuenta de la existencia alienada y alienante del sujeto colonial americano y de la búsqueda del amor ideal y de la transgresión erótica, entre otros temas.

Carlos Orlando Nállim en «Zama: entre texto, estilo e historia», un estudio que data de 1972, señalaba:

En un marco histórico y geográfico de fines del siglo XVIII, asistimos al vaivén vital de un hombre angustiado por muchos conflictos tan íntimos, tan humanos, que de verdad escapan a ese marco histórico-geográfico para actualizarse, para

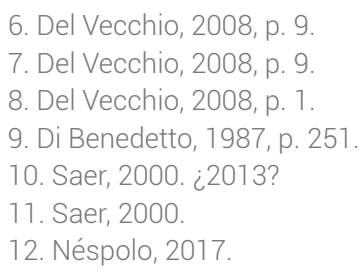


universalizarse, puesto que tales conflictos son tan actuales como el hombre, a lo largo de los tiempos, ya que su punto de partida y su natural posada es el hombre ${ }^{13}$.

La idea es compartida por Saer, quien compara la novela de Di Benedetto con La náusea y El extranjero, «obras mayores de la narrativa existencialista» ${ }^{14}$ por «ciertos aspectos de su concepción narrativa» ${ }^{15}$. Del Vecchio desarrolla también esta línea de lectura al señalar que «la novela existencialista de Sartre y de Camus resuena en las páginas de Zama» ${ }^{16}$, donde el protagonista, en un movimiento de vaivén ${ }^{17}$ «oscila entre la sospecha de ser víctima de aquel determinismo inexorable» ${ }^{18}$ y la conciencia de «poseer libre albedrío» ${ }^{19}$.

Recientemente, a raíz de la exhibición de Zama, el filme de Martel, el redactor de la revista virtual Kunst, bajo el seudónimo de Tenebras Lux, reafirmaba la lectura alegórica, emparentándola con El desierto de los tártaros, de Dino Buzzati, o La mujer de la arena, de Kobo Abe: «En todos los casos, se trata de forzar una situación realista hasta volverla absurda, con la consecuente reflexión a propósito de la angustia y el sinsentido, que autores como Franz Kafka o Albert Camus supieron incorporar a su propia imaginería, para volverse sus mejores exponentes» ${ }^{20}$.

Es relevante mencionar que Antonio Di Benedetto, en la entrevista que le concedió a Günter Lorenz en 1972, afirmó haber realizado una exhaustiva investigación de la orografía, la hidrografía, la fauna, las familias indígenas, la medicina, el guaraní, las costumbres domésticas, las fiestas, el plano de la ciudad principal21. Pero, prosigue, un día decidió «tirar toda esta información por la borda» 22 y prefirió ponerse a escribir directamente, sin consultar ningún libro ni apuntes, ni siquiera en el momento de corregir o pulir. En la entrevista, Di Benedetto explicita de manera muy enfática su rechazo a la reconstrucción fiel del momento histórico, así como su despreocupación ante «cualquier tacha de anacronismo, imprecisión o malversación de datos reales». Y casi como si se tratara de una declaración de principios y una advertencia a los críticos para que no yerren en sus lecturas, determinó: «Mi novela no es histórica, nunca quiso serlo» ${ }^{23}$. Del Vecchio, quien cita ampliamente la referida entrevista, considera que el impulso documentario, aunque desestimado rápidamente «deja, sin embargo, su huella» ${ }^{24}$. Y, en efecto, desde el inicio hasta el

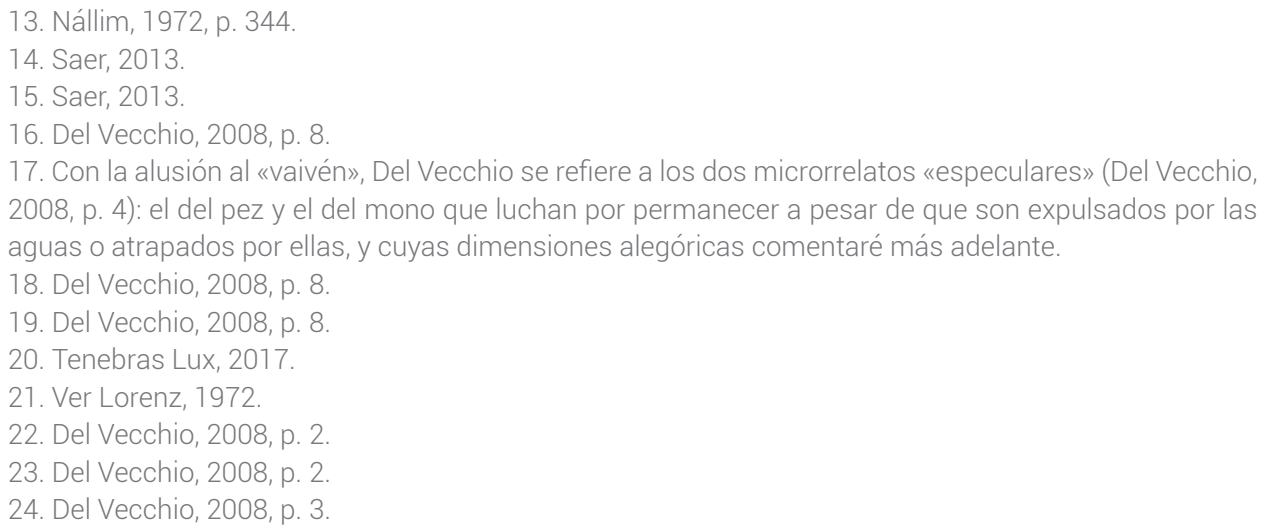


final de la novela, abundan las referencias espaciales y temporales. Aunque nunca se mencione Paraguay o Asunción, sí se nombran lugares del «centro» de los virreinatos como Lima, Buenos Aires, Santiago de Chile, y de España; e incluso aquellos periféricos como Villa Rica y Concepción. Con mucha frecuencia se refieren vocablos de la lengua guaraní, nombres de los diversos grupos indígenas: mbayas, guanaes, caagues. Asimismo, la novela está dividida en tres partes que corresponden a tres años: 1790, 1794 y 1799, que nos remiten al periodo histórico en el que se fueron gestando las luchas por la emancipación. Como acertadamente señala Del Vecchio:

La espera de Diego de Zama tiene su correlato histórico en la espera de los americanos a fines del siglo XVIII. Las reformas administrativas de los Borbones determinaron la política colonial de la época: Carlos III establece un régimen de intendencias que sustituye la figura del corregidor por la del gobernador intendente, resta atribuciones a los cabildos municipales y posterga a los criollos en los puestos jerárquicos, ocupados ahora casi exclusivamente por los españoles. Pocos años después, a causa de su descontento, los criollos relegados como Zama gestarán los movimientos independentistas ${ }^{25}$.

Carlos Orlando Nállim, contradiciendo incluso a Di Benedetto, afirma que Zama puede ser tratada como novela histórica pues «los confines de la historia están claros y la participación del lector en ella, asegurada» ${ }^{26}$ aunque Diego de Zama, «corregidor, juez, valiente u hombre degradado que espera sin esperanzas» ${ }^{27}$, no resista comparación con personajes históricos» ${ }^{28}$. Pero también le otorga relevancia a los valores existenciales y universales que, a su juicio, propone la novela al señalar que, en un marco histórico y geográfico de fines del siglo, asistimos al drama de un hombre «angustiado por muchos conflictos tan íntimos, tan humanos, que de verdad escapan a ese marco histórico-geográfico para actualizarse, para universalizarse ${ }^{29}$.

Tal vez el énfasis puesto en la valorización de Zama como una novela que trasciende el marco histórico, explique la poca relevancia que se le ha asignado al análisis de los conflictos inscritos en el contexto en el que se desarrolla la trama. Si se les presta atención, estos devienen en un motivo que permite ver en los hechos históricos pasados alegorías del presente de los lectores sudamericanos y, particularmente, de los argentinos. Un buen ejemplo de este acercamiento es el que propone Gonzalo Basualdo en «Zama, hombre de ningún lugar, o la tradición en construcción» y que considero cercano al de Martel en lo referido a la identidad negada de Zama, su ser americano.

De acuerdo con Basualdo, Zama se inscribe en la discusión sobre la esencialidad del ser nacional, sobre la posibilidad de una cultura nacional y, más específicamente, sobre la posibilidad de una literatura argentina, temas que Borges propone

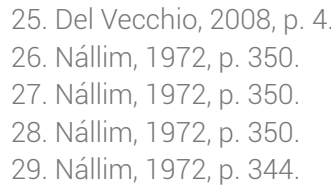


en «El escritor argentino y la tradición» ${ }^{30}$, y señala que Di Benedetto, desde Mendoza, «retoma la conclusión principal del escritor porteño: no hay posibilidades para los argentinos de vallar su cultura; nuestra tradición está abierta (debe estarlo) a toda la cultura occidental» ${ }^{31}$. Zama postula, entiende Basualdo, la imposibilidad de una región, de una localización, por cuanto «Presionado por una conciencia que le indica que debe buscar otro lugar, Zama queda encerrado en el no lugar mismo» ${ }^{32}$. De allí la propuesta de una lectura basada en dos hipótesis, explica Basualdo: la primera es que no hay posibilidad para la realización de una zona, o región determinada, ya que Diego de Zama espera que esta llegue de afuera de ese lugar. La segunda hipótesis se relacionaría con la primera en términos de identidad: si no es posible el encuadre de Zama en ninguna región, la lengua y su apropiación, la escritura, como forma de identidad, tampoco sería posible, considerando el desmembramiento de sus extremidades. En suma, Zama no puede construir su lugar en la región que habita y se halla inmerso en una paradoja: quería el amor de una mujer europea, estando en América, y termina consumando su amor con una mulata; deseaba recuperar su hijo y su esposa, también ausentes en Asunción, y culmina su experiencia amorosa teniendo un hijo con una española residente en América; luego, Zama queda sin ese hijo, tan americano como él. Zama no tiene, ni desea, nada que esté a su alcance, por eso no se apropia de su lugar y de su identidad; por eso, le resulta imposible ser americano ${ }^{33}$.

Esta imposibilidad de Diego de Zama de construir su lugar y forjar su identidad como americano refiere, qué duda cabe, a la llamada «cuestión criolla», a la que me referiré enseguida y que considero fundamental en la interpretación de Martel.

\section{LA CUESTIÓN CRIOLLA}

Sobre la llamada «cuestión criolla» Martina Vinatea siguiendo a Lavallé refiere que el término «criollo» había empezado a emplearse en la década de 1560, primero en el virreinato de Nueva España y, hacia 1567, en el Perú, en el mismo sentido que «indiano», para referirse tanto a aquellos que habían nacido en América como a quienes habían hecho fortuna en ella, pero que regresaron a España. En algún momento, el uso de la voz «criollo» se extendió a España, pero designaba a mulatos, mestizos de español e indígena, indios aculturados; finalmente, se aplicó a los hijos de españoles nacidos en el Nuevo Continente ${ }^{34}$. Así, el término va cargándose de connotaciones negativas pues, como señala Vinatea citando a Mazzotti, «a la codicia desmedida de la que se acusó a sus padres, se sumaban los cargos de un espíritu relajado, levantisco e indisciplinado en los retoños»35. Bernard Lavallé, en «Espacio y reivindicación criolla» atribuye la desvalorización de los nacidos en América por parte de los españoles a su percepción del medio geográfico:

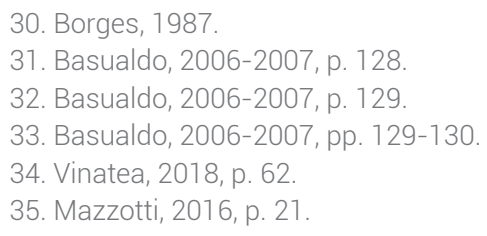


En general, el medio americano se consideraba como de calidad inferior al de Europa y, sobre todo, de España. Por consiguiente, no podía menos que tener efectos sobre todos los seres que en él vivían. Las plantas, los hombres, los animales que allí se transportaban, sufrían, pues, un deterioro notorio, un debilitamiento biológico importante, una disminución de sus facultades, hasta, en el caso de los humanos, una degeneración moral ${ }^{36}$

Del mismo modo en que los indios nacidos en los territorios malsanos sufrían un paulatino deterioro, los criollos «que habían nacido y vivían en América y cuyas familias se perpetuaban en ella hacía varias generaciones, pronto se encontraron implicados y englobados a su vez en ese conjunto de prejuicios desvalorizantes» ${ }^{37}$ e incluso en el siglo XVII, muchos especialistas españoles «se preguntaban sin rodeos si, con el tiempo, bajo los efectos de la naturaleza americana conjugada con condiciones de vida particulares y con influencias astrales específicas, los criollos no vendrían a ser un día semejantes, en todo, a los indios» ${ }^{38}$. Este contexto de desvalorización del espacio americano y de sus habitantes sufre un gran viraje, señala Lavallé refiriéndose específicamente al caso peruano, a partir de 1630. Desde entonces, los nacidos en América se empeñan en afirmar su identidad criolla desde una clara postura reivindicativa: «No existe prácticamente obra peruana de envergadura que no dedique varios de sus capítulos, entre los más significativos, al marco geográfico en que había nacido y vivido su autor» ${ }^{39}$. Se trata, evidentemente, de un recurso empleado para replicar los ataques peninsulares: exaltando las diferentes regiones del continente y describiéndolas elogiosamente, los criollos buscaban demostrar que «al espacio y al medio americanos arquetipos de todas las perfecciones, correspondían hombres perfectamente dotados en todos los aspectos» ${ }^{40}$. Posteriormente, señala Lavallé, los autores criollos dejan de interesarse en destacar la geografía, celebrar los descubrimientos, las aventuras y maravillas del Nuevo Mundo, para ensalzar las ciudades, el medio urbano: son, «ante todo, hombres de la ciudad nunca tan a gusto como cuando se trata de describir la suya, sus calles, sus monumentos, sus plazas y paseos» ${ }^{41}$. Los elogios son tan desmesurados que «nos cuesta trabajo apreciar la realidad de las cosas y sus proporciones»42. La ciudad en la que nacieron es la razón «de su orgullo de ser criollos»"43. Otra observación relevante es la que refiere a la ausencia del indio en la literatura del siglo XVII comparada con su presencia en las obras españolas del siglo XVI, donde había ocupado un lugar privilegiado, mientras que en las pocas páginas en las que son mencionados, aluden «al pasado y a los esplendores del imperio inca a los que, por lo demás, el indio parece ajeno» ${ }^{44}$

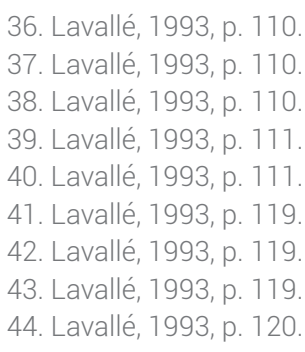


Empeñados en afirmar su propia dignidad en el marco del esplendor urbano y en situar a su país natal por encima incluso de la metrópoli, y «conscientes del mecanismo en que se apoyaban muchos prejuicios de los que eran víctimas, los criollos se esforzaron por subrayar en sus descripciones todas las posibles razones de su orgullo americano, todo cuanto combatía y contradecía el desdén del que, a través de su región, ellos eran objeto en las concepciones colonialistas europeas» ${ }^{45}$. En su país, y aun cuando ignoraran gran parte del territorio y a quienes allí vivían, los autores exaltaban el continente: todo «todo es extraordinario, sorprendente, enorme en el sentido más amplio de la palabra, inaudito, milagroso, maravilloso»46. Europa era «aquel continente lejano en que los criollos todavía pensaban tener una parte de sí mismos pero que los juzgaba sin benevolencia» 47 , de allí que "conscientes del mecanismo en que se apoyaban muchos prejuicios de los que eran víctimas, los criollos se esforzaron por subrayar en sus descripciones todas las posibles razones de su orgullo americano, todo cuanto combatía y contradecía el desdén del que, a través de su región, ellos eran objeto en las concepciones colonialistas europeas» ${ }^{48}$.

El conflicto determinante, señala Rodríguez Garrido, aquello que «marcó sin duda un hito en la evolución del pensamiento criollo en América» ${ }^{49}$ tiene su origen en un hecho concreto que se produce cuando la Corona cambia la política en torno a la designación de los cargos. Hasta entonces, el reparto «fue atributo del virrey, pero hacia la década de 1680 este poder se concentra en la Corte de Madrid» ${ }^{50}$. La medida tuvo como efecto, prosigue Rodríguez Garrido:

un paulatino incremento de la posesión de estos cargos en manos de peninsulares advenedizos, quienes llegaban a los territorios americanos con un nombramiento tramitado y adquirido en España. En cambio, los criollos descendientes de los antiguos conquistadores vieron cada vez más reducidas sus posibilidades de adquirir tales cargos, a causa del costo que implicaba el viaje, la estadía en la metrópoli y los trámites allí. [...] A partir de ese momento, a la consabida defensa del ejercicio intelectual en el Nuevo Mundo que había caracterizado a los textos criollos desde la primera mitad del siglo XVII, se unirá muchas veces una argumentación en favor de los derechos de la elite criolla a gozar de los beneficios económicos derivados de la administración colonial ${ }^{51}$.

Las cartas al rey escritas por el duque de la Palata cuando fue virrey en el Perú, así como las del conde de la Monclova, virrey de Nueva España y luego del Perú, están documentadas por Rodríguez Garrido. En ellas, intentan convencer a la Corona de la necesidad de que el virrey recupere el derecho al nombramiento de cargos y oficios. El 15 de junio de 1690, el conde de la Monclova le escribe al rey desde Lima una carta en la que precisa que le ha enviado otras anteriormente: México,

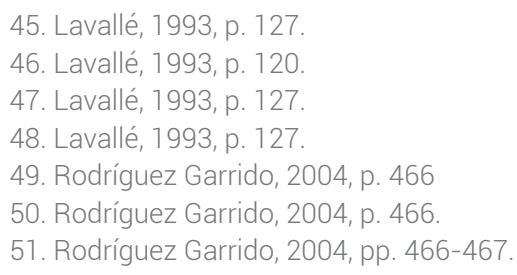


15 de enero de 1688 y Lima, 28 de setiembre de 1689. En ella, el virrey insinúa que una «política sobre este punto no solo perjudica la imagen de autoridad del virrey, sino que también arriesga finalmente la del monarca a quien aquel representa» ${ }^{52}$. Asimismo, defiende «la necesidad de que los descendientes de los primeros pobladores y conquistadores españoles reciban estos cargos para "mantenerse con decencia" y advierte sobre los méritos de aquellos que no pueden ir a la Corte a tramitar beneficios» ${ }^{53}$. Este cambio de política en la asignación de los cargos y oficios agudizó el enfrentamiento de la élite criolla, los grupos de poder local y el virrey con la Corona. Se trataba de un viejo enfrentamiento iniciado con la dación de las Leyes nuevas de 1542, cuyo propósito fue proteger a los indígenas y organizar administrativamente las nuevas tierras. Las leyes nuevas también buscaron, como se sabe, eliminar el sistema de las encomiendas que había enriquecido y empoderado a los conquistadores, quienes consideraban que la Corona estaba en la obligación de otorgarles tierras como premio a su esfuerzo ${ }^{54}$. Las leyes nuevas limitaron el poder de los conquistadores a favor del control de la Corona y aunque el pacificador Pedro de La Gasca, enviado por el rey, derogó algunos de los puntos más radicales, los conquistadores y sus primeros descendientes se sintieron maltratados y despojados de lo que con justicia les correspondía. Con el paso de los años, ya en el siglo $\mathrm{XVII}$, las reivindicaciones de los criollos se centraron en el tema de sus derechos a ocupar cargos públicos, mercedes y otras prerrogativas como descendientes de los conquistadores y por encima de los peninsulares que llegaban como parte del séquito de los virreyes. Ilustra este conflicto la carta que Lope García de Castro, gobernador del Perú por ausencia del virrey, escribe al presidente del Consejo de Indias lo siguiente:

\footnotetext{
Vuestra excelencia entienda que la gente de esta tierra es otra que la de antes porque los españoles que tienen que comer en ella, los más de ellos son viejos y muchos se han muerto y han sucedido sus hijos en los repartimientos y han dejado muchos hijos, por manera que esta tierra está llena de criollos que son estos que acá han nacido y, como nunca han conocido al rey ni esperan conocerlo, huelgan de oír y de creer a algunos malintencionados, los cuales les dicen: ¿cómo sufrís que habiendo vuestros padres ganado esta tierra hayan de quedar vuestros hijos perdidos, pues en vosotros se acaban las dos vidas? Y a los que no tienen indios les dicen que ¿cómo se sufre que anden ellos muertos de hambre, habiendo sus padres ganado esta tierra?, y con esto los traen desasosegados [... $]^{55}$.
}

Las constantes demandas al rey, el resentimiento de los criollos ante la discriminación que padecían, su paulatino alejamiento de la distante y maltratadora metrópoli que dio lugar a la necesidad de reivindicar su ser americano y de exaltar el lugar en el que nacieron, atravesaron a todas las colonias y las condujeron, irremediablemente, a las luchas independentistas en el siglo XIX. Y en este contexto de 
fricciones y resentimientos transcurre la trama de Zama centrada, particularmente, en el conflicto por los nombramientos de los cargos públicos. La larga e inútil espera de Diego de Zama da cuenta, de manera implícita, de la intervención del rey en desmedro de la autoridad del virrey. La orden de traslado tiene que venir de España y tardará, como le explica el gobernador a don Diego, varios años: «Su Majestad nunca atiende este tipo de pedidos la primera vez. Pero es necesario hacerlos. Después de un año o dos lo renovaremos. Entonces sí lo considerará»56.

Sin embargo, a diferencia de los criollos que se asumieron como tales y lucharon por su reivindicación y emancipación de la metrópoli, don Diego de Zama se construye, como un criollo que se resiste a aceptarse como tal. Su resistencia a aceptar su identidad americana, su afán de ser aceptado como un español, su paciente espera (pero también, en la novela, sus errores, como se verá luego) conducen a Diego de Zama al aislamiento que, en la versión de Di Benedetto, lo llevará a la muerte. En la película, en cambio, Martel postula, a mi entender, una nueva vida posible, justamente cuando don Diego abandona el sueño español.

\section{DE ZAMA DE DI BENEDETTO A ZAMA DE MARTEL}

Citando a Legaz, Basualdo señala que Zama de Di Benedetto explora los conflictos velados entre españoles y americanos, «pero con americanos como Zama que ignoran las angustias de los hombres de su tierra y se sienten inmersos en los conflictos españoles» ${ }^{5}$. También, como varios autores lo han mencionado, la espera de Diego de Zama puede entenderse como la espera de los americanos, su descontento y la marginación a la que fueron sometidos. La «cuestión criolla» que aparece de manera manifiesta en algunos episodios de la novela a los que me referiré enseguida, en la versión de Martel constituye el eje en torno al que gira su propuesta de adaptación, como intentaré demostrarlo considerando las líneas básicas desarrolladas en la trama: la situación laboral de Diego de Zama y su relación con las mujeres, enmarcadas ambas líneas en la metáfora del pez con la que se inician los créditos, y en la escena final, con Zama internándose en la selva.

\section{1. «Hay un pez, en ese mismo río, que las aguas no quieren»58}

La historia de este pez, que «debe pasar la vida, toda la vida»59, luchando constantemente por permanecer en medio de aguas que lo rechazan, la cuenta en el filme un mulato acusado de haber matado a una mujer. Su relato en «off» es ilustrado con un primer plano de peces en movimiento mientras se suceden los títulos de crédito. Antes, a manera de prólogo, el filme nos ha mostrado a un Diego de Zama solitario mirando el mar y que luego, seducido por voces y risas femeninas, las sigue hasta descubrir que pertenecen a un grupo de mujeres que desnudas retozan

56. Di Benedetto, Zama, p. 149

57. Legaz, 1991, p. 261

58. Di Benedetto, Zama, p. 10.

59. Di Benedetto, Zama, p. 10. 
en la orilla del río. Zama las observa escondido, con sigilo y placer contenido, pero súbitamente una de ellas lo descubre y lo acusa a gritos: «mirón» ${ }^{60}$. Escapa, humillado y cuando ella lo alcanza, la golpea. Lo vemos luego en su oficina de la gobernación, dictando una carta al escribiente: «Marta, ya falta poco para que vuelva»61; y más tarde, desconcertado, atendiendo el caso del acusado que relata la historia del pez instigado por Ventura Prieto, funcionario inferior a Zama pero nacido en España, y que cumple un rol determinante en la línea que me propongo desarrollar.

En la novela, mientras Diego contempla absorto a un mono muerto y reflexiona: «El agua quería llevárselo y lo llevaba, pero se le enredó entre los palos del muelle decrépito y ahí estaba él, por irse y no, y ahí estábamos. Ahí estábamos por irnos y no»62, se acerca Ventura Prieto y, al verlo ensimismado, le relata la historia del pez.

Valiéndose de ambas imágenes, la del pez que el agua rechaza y la del mono que «está por irse y no» ${ }^{63}$ en el agua que fue «siempre una invitación al viaje» ${ }^{64}$, Di Benedetto establece el drama de Diego de Zama: como el mono muerto, está paralizado y carece de la capacidad para liberarse; como el mono, está atrapado por sus impulsos tanto como por su egoísmo, violencia y progresivo envilecimiento. Comete errores muy graves. Inicia una riña con Ventura Prieto por una sospecha sin asidero: «Le apliqué dos recios bofetones sin indagar más» ${ }^{65}$; es descortés con el gobernador y no lo felicita por su ascenso y viaje a España: «Él quería enterarme, después de haberme conmovido con su insinuación de favores, y yo debía afectar regocijo y prodigarle zalemas» ${ }^{66}$. No se comporta como se espera y pierde «al abogado de mayor predicamento que pude tener en Madrid» ${ }^{67}$. Deja morir a su amigo el oriental sin mostrar hacia él un mínimo de solidaridad; no hace el menor esfuerzo por defender al ebrio dormido por cuyo rostro se arrastra una peligrosa araña. Asimismo, persigue mujeres e incluso acosa a Luciana, de quien solo le interesa su cuerpo. Pero cuando ella le confiesa que «Todos los hombres codician mi cuerpo. Honorio, mi propio esposo, vive fascinado por mi carne. Yo lo desprecio y desprecio a todos los hombres por su amor de posesión»68, decide apartarse de ella: «Nada más me importaba de esa mujer iletrada, de rostro incapaz de sugerir emociones amables» ${ }^{69}$. Hablar con Luciana le produce hastío. Pero cuando la ve por primera vez, fascinado con la belleza de su cuerpo y la promesa de poseerla, está dispuesto a renunciar a todo cuando imagina, en una suerte de sueño diurno, que se encuentra en la calle con Su Majestad y este le propone: «"Zama ¿quieres cargo en Buenos Ayres, mejor visto y rentado, si es que aceptas partir mañana?" Le habría respon-

\footnotetext{
60. Martel, Zama.

61. Martel, Zama.

62. Di Benedetto, Zama, p. 9.

63. Di Benedetto, Zama, p. 9

64. Di Benedetto, Zama, p. 9

65. Di Benedetto, Zama, p. 59.

66. Di Benedetto, Zama, p. 82.

67. Di Benedetto, Zama, p. 82.

68. Di Benedetto, Zama, p. 63.

69. Di Benedetto, Zama, p. 64.
} 
dido: "Todavía no"»70. Así, en la novela, atrapado por sus deseos e impulsos, Zama no conseguirá salir del confinamiento en que se encuentra; tampoco refundar su hogar junto a Marta y sus hijos, "con la antigua bonanza» ${ }^{71}$, no solo porque su condición de criollo lo desfavorece sino a causa de sí mismo:

Yo estaba disconforme con mi comportamiento. Aunque achacaba mis desórdenes a potencias interiores irreductibles y a un juego de factores externos inescrutables, invisiblemente montados para provocar mi turbación. Este cerco inductor, pensaba yo, en determinado momento me volcaba en actos no deseados, ocasionalmente seductores y capaces de transformarse, a posteriori, en algo repelente y abominable ${ }^{72}$.

En la versión de Martel, la metáfora de Diego de Zama es la del pez que lucha por la «conquista de la permanencia» ${ }^{73}$, aquel que debe pasar la vida en vaivén, empeñado en estar ahí donde nadie lo quiere, luchando «constantemente con el flujo líquido que quiere arrojarlo a tierra» ${ }^{74}$. Como el pez que se resiste a abandonar el agua que lo repele, Zama se resiste a abandonar su proyecto y espera: llegará la carta del rey, lo trasladarán a Lerma, España, se reunirá con su mujer e hijos. En suma, será tratado como un funcionario respetado y leal al monarca: como un español, no como un criollo. Y no es que este aspecto de Zama esté ausente en la novela, solo ocurre que Martel acentúa el peso de la metáfora de la lucha por la permanencia en un lugar que lo rechaza para enfatizar en la inutilidad de este esfuerzo condenado al fracaso. De allí que el Zama de Martel aparezca representado más como una víctima que como un ser ambivalente, egoísta e incluso cruel atrapado en sus oscilaciones de carácter y deseos, como en la novela. El de Martel es un ser desconcertado, uno que no entiende muy bien lo que pasa a su alrededor y que se expresa en el uso del sonido «off»: voces, murmullos, palabras en guaraní, risas, gritos. Al igual que Diego de Zama, tampoco los espectadores entendemos qué ocurre, dónde estamos, qué sucede exactamente ni por qué.

Como el narrador de la novela de Di Benedetto es el propio Zama y todo lo que sabemos los lectores está mediado por su voz y su mirada, solo vemos lo que él ve. Martel buscó crear un efecto similar en el filme:

Había una idea de mantenernos adentro de la cabeza del personaje con pequeñas apuestas, entre ellas la idea de que muchos textos de diálogo estuvieran sobre planos de Zama. Me parecía que la repetición de ese dispositivo iba a generar una especie de voz interior hecha de muchas voces. Genera la sensación de que la película es muy subjetiva y que todo lo que estás viendo está dentro de la cabeza del protagonista, como un soliloquio ${ }^{75}$.

70. Di Benedetto, Zama, p. 29.

71. Di Benedetto, Zama, p. 88.

72. Di Benedetto, Zama, p. 87.

73. Di Benedetto, Zama, p. 9.

74. Di Benedetto, Zama, p. 9

75. Anónimo, «En Zama "hay una necesidad de demencia para pertenecer a la sociedad"». 
Pero a diferencia de la novela, donde lo que sabemos, está mediado por la mirada de Zama, en el filme lo vemos con la mirada de la cámara: asistimos al deterioro progresivo de su aspecto y de su ropa; observamos, sin su intermediación, los lugares donde vive; vemos la expresión de su rostro que muestra la vulnerabilidad de un hombre perdido en un mundo que no siente suyo, que no entiende y del que solo quiere partir. Bien lo señala Martel en la entrevista ya citada en la que lo describe como un burócrata mediocre que se ve obligado a

hacer cosas que preferiría no hacer, traicionando, afirmando lo que no cree, actuando como si sus días no fueran parte de su vida sino un interludio que hay que soportar hasta que llegue su esperado traslado para reencontrarse con su familia ${ }^{76}$.

España «no le quiere»77. Pero Zama, como el pez, se pasa la vida «luchando para que el agua no le eche» ${ }^{78}$, siempre al borde; siempre a punto de ser expulsado.

\section{2. «¿Estaré hablando con un español o un americano?»79}

Una escena que Martel toma de la novela, aunque con cambios que comentaré en seguida, sintetiza el lugar de don Diego de Zama en la alejada gobernación en la que se encuentra confinado pese a que cuando fue nombrado se le insinuó que implicaba «un fugaz interinato» 80 . Pero, ya se ha dicho, el tiempo pasa y la carta del rey no llega. En la escena de la novela participan don Diego de Zama a nombre del gobernador, quien no ha querido atender «a esa gente» ${ }^{81}$ porque, según sus conocimientos, es «terriblemente pedigüeña» ${ }^{2}$; Ventura Prieto, asesor letrado en asistencia; «dos ancianos pulcros, y una joven bonita, sencilla y notoriamente pasiva» ${ }^{83}$, huérfana de padre y madre "a causa de un acto sanguinario de los indios» ${ }^{84}$. El anciano se presenta como antiguo descendiente de adelantados, descendiente en línea directa de Domingo Martínez de Irala ${ }^{85}$ y declara encontrarse en la miseria pues no puede trabajar las tierras heredadas. Para ello, precisa una encomienda de indios. Sin pedirle documentación probatoria de su ascendencia, el asesor letrado determina: «Puede volverse en paz vuesa merced a su tierra, que tendrá encomienda de indios en nombre de Su Majestad» ${ }^{86}$. Cuando la familia se va, Ventura Prieto muestra su desacuerdo: «Se atrevió a opinar sobre mi pronunciamiento en el caso

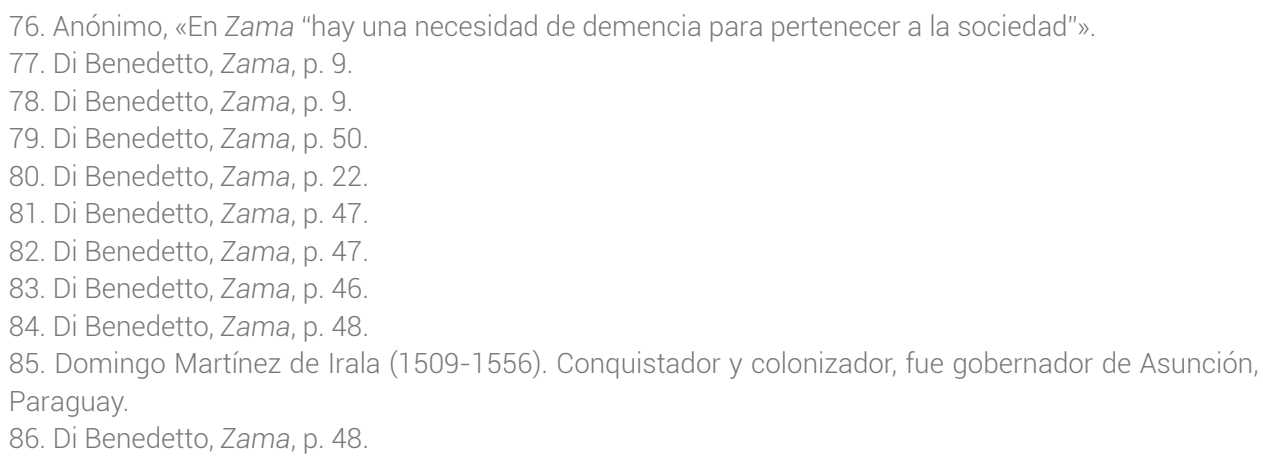


[...]. Dijo que para privar de la libertad a cien o doscientos nativos y hacerlos trabajar en provecho ajeno no era mérito suficiente un papel antiguo con el nombre de Irala» ${ }^{87}$. Como Zama no está seguro si Prieto critica su «disposición favorable al anciano o el régimen de las encomiendas»88, le preguntó «cuál título consideraba válido para obtener la encomienda» 89 . La respuesta desconcierta a Zama: «Ninguno. Y menos que todos el de la herencia remota» 90 .

Es claro acá que Ventura Prieto está cuestionando el viejo sistema de las encomiendas que benefició a los conquistadores y a sus descendientes y que, como se ha visto, se intentó erradicar con las controvertidas Leyes Nuevas desde finales del XVI. Ventura Prieto, español del siglo XVIII, y nombrado por el rey, ya no por el virrey, representa a la metrópoli y su viejo conflicto con las colonias en su defensa de los indígenas frente a los abusos de los conquistadores y sus descendientes, que quisieron apropiarse de las tierras descubiertas y conquistadas. El viejo descendiente de Irala, ya sin indios, es ciertamente un criollo a quien Prieto califica de explotador, como lo fueron sus antepasados aventureros. Zama considera que estas opiniones son «peligrosas» ${ }^{91}$ pues a su juicio, van contra la corona y comenta/pregunta, no sin cierta malicia: «¿Estaré hablando con un español o un americano?»92. Es claro que no está refiriéndose al pasado de las encomiendas, sino al presente de los descendientes, a los criollos que ya amenazan a la metrópoli con su descontento, sus frustraciones y afanes independentistas. La respuesta es contundente e insultante: «iEspañol, señor! Pero un español lleno de asombro ante tantos americanos que quieren parecer españoles y no ser ellos mismos lo que son» ${ }^{93}$, cuestionando su falta de solidaridad con los indígenas, tan americanos como él. Zama, en la novela, con furia naciente, pregunta: «¿Va por mí?» ${ }^{94}$, a lo que Prieto, luego de vacilar un instante, responde: «no», que es un «sí» no pronunciado. Y acá termina la escena.

En el filme destacan algunas diferencias relevantes que aportan a la tesis de este trabajo. De un lado, además de los personajes ya citados, participan cuatro jóvenes indígenas; la huérfana, que es mestiza, y un perro que lame sus manos. Ventura Prieto cumple la función de «asesor en asistencia» y el viejo descendiente y su mujer explican su situación en los siguientes términos:

-Somos antiguos pobladores de Concepción. Descendientes de adelantados, compadre en línea de sangre de don Domingo Martínez de Irala. Hemos corrido a los indios de estas tierras, pero han vuelto con pretensiones. Los hemos vuelto a correr y así. Se han escapado a la selva; los fuimos a buscar y no tuvimos piedad ${ }^{95}$.

87. Di Benedetto, Zama, p. 50.

88. Di Benedetto, Zama, p. 50.

89. Di Benedetto, Zama, p. 50.

90. Di Benedetto, Zama, p. 50.

91. Di Benedetto, Zama, p. 50

92. Di Benedetto, Zama, p. 50.

93. Di Benedetto, Zama, p. 50.

94. Di Benedetto, Zama, p. 50

95. Martel, Zama. 
Y prosigue la esposa:

-No ha quedado ni uno y no hay quien trabaje. Solo me queda mi nieta, que es mezcla. Estuvo cautiva. La hemos podido recuperar. Es nuestro derecho recibir encomienda. Cuarenta indios mansos ${ }^{96}$.

La cámara registra a la joven mestiza cuyas manos lame el perro, acto cargado de erotismo desde la mirada de Zama, quien, inquieto, vuelve una y otra vez a contemplarla, y a un Ventura Prieto crítico, disconforme y atento a sus reacciones. Tras determinar que «indios no van a faltar» ${ }^{77}$ y que el gobernador enviará los pliegos del pedido a Su Majestad, la familia abandona la sala. Quedan Zama y Ventura Prieto y se desarrolla un diálogo bastante similar al de la novela. La diferencia es que la escena continúa. Tras la contundente e insultante respuesta de Ventura Prieto, Zama se lanza sobre él y le pega. En lugar de responder, Ventura Prieto se burla del criollo: "Qué bravura. Me han dicho que casi atrapa a Vicuña Porto» ${ }^{98}$, lo que provoca aún más la furia de don Diego y expulsa, con golpes y patadas a un inerme Ventura Prieto.

Martel hace referencia a la difícil colonización, a los conflictos entre indios, encomenderos y la metrópoli, así como al mestizaje producto ya sea de las violaciones o relaciones consentidas, como la de Zama con Emilia, que es indígena, tema que Di Benedetto no explicita y se verá luego. Asimismo, visibiliza de manera más enfática el conflicto entre españoles y criollos nacidos en el continente. La mayoría, si no todos, eran mestizos, pues los primeros conquistadores, como señala Cañedo-Argüelles, no tuvieron ningún problema en procrear hijos con indias y reconocerlos como legítimos. En los siglos venideros, ya cuando la colonización se hubo afirmado, el grupo mestizo-español rechazó a los indígenas y se autoconsideró «español», tratando de adecuarse «a los patrones culturales hispanos» ${ }^{99}$; pero es evidente que los «nacidos en España» 100 , funcionarios como Ventura Prieto, el Gobernador e incluso Luciana, no reconocen como sus iguales incluso a criollos como Diego de Zama, el único funcionario americano en la administración de la provincia y de lealtad probada, que ansía que lo trasladen a Lerma, España y que se precia (aunque miente) de desear solo a mujeres blancas y españolas. En este sentido, también es relevante que Martel convierta a Emilia, la viuda española con la que Zama tiene un hijo en la novela, en una indígena: es significativo pues presenta claramente el tema del mestizaje considerado ilegítimo en el XVIII.

La agresión física a Ventura Prieto, en la novela, ocurre en otras circunstancias: Zama sospecha, equivocadamente, que este se burla de él cuando le menciona al 
«niño rubio» ${ }^{101}$ y le aplica «dos recios bofetones» ${ }^{102}$. Ventura Prieto reacciona y se enfrascan en una dura pelea que culmina con el triunfo de Zama: «Lo agarré de los pelos y di tres veces su cabeza contra las rejas [...] y todavía enceguecido por saberme dominante, atiné a sacar el cuchillo del costado y le hice un tajo en la mejilla» ${ }^{103 .}$ El gobernador le hace saber que ha puesto en prisión a Ventura Prieto y lo ha destituido. Y equivocadamente, Zama entiende: «que la partida estaba ganada, aunque Prieto fuese español y yo americano. Operaba la solidaridad de estado»104. Pero luego el gobernador le comunica que ha decidido exiliar a Ventura Prieto permitiéndole elegir el lugar donde se establecerá. Al enterarse que Prieto escogió Santiago de Chile, comprende que su enemigo ha sido beneficiado. En la película, la arbitrariedad del gobernador y su favoritismo a Prieto son más explícitos: «Ventura Prieto es funcionario español y ha elegido su destino»105 anuncia. «iEl deportado elige su destino?»106, pregunta un desconcertado Zama. «Sí. Ha elegido Lerma» 107. $Y$ los espectadores sabemos que a Lerma es donde don Diego desea ser trasladado. Conviene destacar que, en la novela, la reacción de Zama contra Prieto es impulsiva y basada en una presunción. En la película, en cambio, es comprensible, porque Prieto lo ofende al referirse, justamente, al conflicto de Diego de Zama: su resistencia a aceptarse criollo, uno de los ejes, se ha dicho, de la lectura de Martel.

También en la tercera parte se destaca la condición de criollo de Zama. En la novela, al igual que en el filme -aunque aquí no se especifica el año y la elipsis se presenta sin ninguna transición- Diego de Zama lleva esperando nueve años el ansiado traslado. Decide entonces pedir plaza para formar parte del regimiento que irá en busca del delincuente Vicuña Porto y sus hombres. Cansado de la lentitud burocrática, piensa que su participación en una empresa de armas «en bien del sosiego de la población» 108 agradaría a Su Majestad, quien lo recompensaría. Y por su condición de ex corregidor, que tiempo atrás había pacificado las tierras, espera tener mando en la expedición. Pero una vez más es postergado por su condición de americano y será el capitán Parrilla, español, el jefe del regimiento. En la película, se enfatiza el autoritarismo del capitán frente a un cada vez más maltratado y marginal Zama que persiste en ser considerado español.

101. La película omite la línea narrativa referida al «niño rubio» que Di Benedetto desarrolla a lo largo de la novela. Se trata de una presencia extraña, que solo él ve en la habitación de su primera vivienda. Luego se menciona al «niño rubio» vinculado con una médica a la que Zama busca para que cure al oriental. Finalmente, aparece en el extraño final que comentaré más adelante.

102. Di Benedetto, Zama, p. 59.

103. Di Benedetto, Zama, p. 59

104. Di Benedetto, Zama, p. 60

105. Martel, Zama.

106. Martel, Zama.

107. Martel, Zama.

108. Di Benedetto, Zama, p. 214.

HIPOGRIFO, 7.2, 2019 (pp. 247-268) 


\section{3. «Más extraña Europa el que nunca estuvo»109}

El incómodo lugar en el que se ubica Diego de Zama como americano que se niega a sí mismo, se evidencia también en su relación con las mujeres. En la novela, se debate entre la fidelidad a Marta, su esposa ausente, y su casi incontrolable «apetencia de mujer» ${ }^{110}$ que lo lleva a espiar en el río, a buscar en la calle a alguna que acceda a sus deseos, sea señora, mujer libre, sirvienta, esclava, e incluso a tener relaciones con una mujer mayor que le ofrece ayuda. Sin embargo, proclama que es virtuoso y que solo acepta relacionarse con mujeres blancas y españolas; indias, mulatas, negras le causan repugnancia. En realidad, evita mirar a las mulatas «para no soñar con ellas» ${ }^{111}$. Luciana, blanca, española y de hermoso cuerpo, lo exalta, y aunque logra algunos avances (un ensoñado «amado» que pronuncia ella luego de un «beso prolongado y jugoso» ${ }^{172}$, lo llama «esposo» y lo besa, pero no le abre la puerta de su alcoba porque es virtuosa), comprende que Luciana juega con él con promesas que no cumple. Una noche, vigilando la casa de Luciana, ve a un hombre que sale a hurtadillas. Es el capitán Bermúdez, español, con quien Zama ha sostenido un diálogo en el que le hace ver que su traslado peligra por haber declarado su preferencia por mujeres blancas y españolas. Este personaje no tiene presencia en la película.

Martel, en el filme, presenta a una Luciana seductora, pero que nunca le concede ni un beso. La relación le permite mostrar a un Zama desconcertado, atormentado por el deseo no satisfecho, de alguien que se ofrece, y no; que lo incita y a la vez lo rechaza. Finalmente, gracias a la sirvienta mulata que le permite ingresar a la casa de Luciana, la descubre en la cama con Ventura Prieto poco antes de su traslado a Lerma. También Luciana volverá a España con su marido, aunque su partida no se narre en la película.

Queda claro que Zama, como americano, es despreciado por Luciana, y justamente en la escena que desarrolla la primera visita de Zama a Luciana, se evidencia una vez más su deseo de ser considerado español. En ella, Luciana se queja del calor, de la falta de teatro y de espectáculos, de la soledad que se siente en los pueblos chicos a diferencia de lo que ocurre en una ciudad grande, de las noticias atrasadas. La respuesta de Zama es tomada del siguiente monólogo de la novela, que en la novela refiere a una reflexión íntima y personal en la que Zama devela no solo su profunda frustración erótica, sino vital, tras la constatación de su propia invisibilidad y frente a la imposibilidad de habitar el continente al que quiere pertenecer:

¿Nunca sería el visitado del amor? No el amor de Luciana, si es que lo conseguía, sino el de una mujer de otras regiones, un ser de fineza y caricias como podía haberlo en Europa, donde siquiera unos meses hace frío y las mujeres usan abrigos suaves al tacto como los cuerpos que cobijan. Europa, nieve, mujeres aseadas porque no transpiran con exceso, y habitan casas pulidas donde ningún piso es de

109. Martel, Zama.

110. Di Benedetto, Zama, p. 72

111. Di Benedetto, Zama, p. 12

112. Di Benedetto, Zama, p. 68

HIPOGRIFO, 7.2, 2019 (pp. 247-268) 
tierra. Cuerpos sin ropas en aposentos caldeados, con lumbre y alfombras. Rusia, las princesas $[\ldots]^{113}$.

Pero en el diálogo con Luciana, en respuesta a sus quejas, las palabras de Zama adquieren otro sentido: el de la añoranza, el deseo de estar donde no puede. Así lo entiende Luciana, quien se limita a mirarlo y a comentar, con cierta suficiencia y aire de superioridad: «Más añora Europa el que nunca estuvo»114.

\section{4. «¿Quieres vivir?»115}

J. Hoberman, en su reseña «Lucrecia Martel, una directora que desconcierta y estremece a sus seguidores», señala:

Di Benedetto se centraba en Zama y su entorno con aspiraciones europeas e ignoraba en su mayoría a la gente y los indígenas esclavizados por la colonia. Martel incluye africanos e indios, principalmente mujeres, en casi cada cuadro. La historia de Zama también es la suya. Un cambio como ese requiere una enorme voluntad y un pensamiento concreto ${ }^{116}$.

Y esto es totalmente cierto, pues Martel visibilizará la presencia indígena en la ciudad y la dramatizará, apoyándose, claro, en un despliegue de imágenes que la novela no describe y haciendo a los indígenas hablar en su lengua, lo que no hace Di Benedetto. Esto ocurre no solo en la tercera parte, cuando Zama forma parte de la expedición en busca de Vicuña Prieto y el grupo se enfrenta a diferentes grupos de indígenas, sino en la ciudad, con los indios mansos. Allí donde Di Benedetto parece más interesado en narrar los tormentos y desesperación de Zama, Martel da protagonismo a los indígenas, destacando su dominio sobre los conquistadores, a quienes les confiscan sus vacas y caballos. A la cineasta le interesa destacar la verdad histórica: hubo zonas inaccesibles a los conquistadores, indígenas rebeldes que no se dejaron dominar. La escena de la multitud de indígenas, que menciona Di Benedeto ( $N o$ una tribu sino muchedumbre» ${ }^{117}$ ) y que Martel desarrolla con mayor detalle, bien podría estar aludiendo a las alianzas temporales realizadas por las diversas tribus guaraníes que historiadores como Cañedo-Argüelles han caracterizado como «comunidades locales independientes» ${ }^{118}$, muy «celosas de su autonomía» ${ }^{119}$, que se alían temporalmente para un fin, como una aventura militar, «pero el espíritu colectivo es esporádico» ${ }^{120}$.

Cuando Di Benedetto se refiere a la expedición que se dirige al norte de Asunción en busca de Vicuña Porto y su pandilla, que había alzado indios tiempo atrás y promovido rapiña, narra la tierra boscosa, la llegada a Ipané; menciona las zanjas

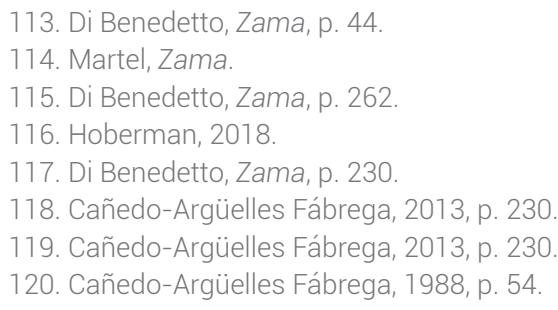


que los curas franciscanos hicieron un siglo atrás para impedir que los indios se fugaran de las misiones franciscanas y nombra a los diversos grupos indígenas: mbayas; guanaes; caagues. Pero en la película, la presencia de los indígenas es dominante y da cuenta, desde la mirada de los expedicionarios, de su desconcierto y de la incomunicación. No hay glamour, valentía; tampoco miedo. Solo desconcierto. Nadie entiende nada. Roger Koza ha notado con acierto que, como si estuviera filmada directamente en 1790, la cámara atestigua las costumbres, el orden social, las creencias, el cuerpo de los hombres, la singularidad del ecosistema ${ }^{121}$.

Finalmente, los indígenas los dejan cerca al río y vuelven a sus tierras. El grupo de expedicionarios descubre que en sus filas, con otro nombre, se encuentra el buscado Vicuña Porto. Todos, excepto el capitán Parrilla y Diego de Zama, se unen a Porto, quien les ofrece ir en busca de unos cocos llenos de cristales preciosos con la ayuda de Zama, que sabe dónde están. Este se niega y los desilusiona: no existen los cocos. Y por decir la verdad, por «hacer con ellos lo que nadie hizo por mí: decir a sus esperanzas, no» ${ }^{122}$, Zama es castigado y le cortan las manos. Este episodio es altamente simbólico e invita a la lectura metafísica, pero desde la perspectiva de este trabajo me interesa destacar la decisión de Diego de Zama de partir río arriba, hacer el camino opuesto al que deseaba: el sur y luego España.

Si nueve años después, Diego de Zama cambia su estrategia y decide tomar las armas para ser premiado por el rey, esta motivación no se explicita en la película. Por el contrario, nos presenta a un Zama visiblemente cansado, desmoronado, sin esperanza. Y la propuesta del filme se distancia claramente de la novela en el desenlace. Mientras que Di Benedetto nos presenta una escena onírica en la que don Diego de Zama yace en una canoa conducida por el «niño rubio», que parece ser su conciencia, Martel muestra a un Zama vivo, que reacciona ante la pregunta del niño indio: «¿Quieres vivir» ${ }^{123}$. Y el criollo, sin manos, contesta afirmativamente. La canoa se dirige río arriba, más lejos cada vez de España.

En una entrevista concedida a la agencia Télam, Martel declaró:

En el fondo está la idea de que cualquier persona que se resiste, perece. Los huracanes a los árboles rígidos los arranca de raíz, mientras que las palmeras se doblan, pero sobreviven. Sólo queda lo flexible. La mejor forma de oponerse a algo malo que te toca vivir es la flexibilidad. Y no creerse tanto algo, porque mutar es la acción más vital posible. No hay que resistir, sino mutar $^{124}$.

Así, Diego de Zama deja de luchar en «el agua que le rechaza» ${ }^{25}$ y se libera emprendiendo el camino opuesto. La propuesta es esperanzadora: será posible construir una sociedad entre indios y criollos. No es arbitrario, en este contexto, que Emilia, la viuda española pobre con la que Zama engendra un hijo, sea indígena en

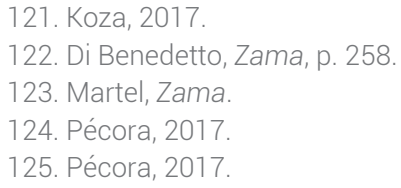


la película, con lo cual parece apostar por la afirmación del ser americano mestizo que se posesiona de un territorio que no pertenece ya a España.

Como se ha visto en la primera parte de este trabajo, si bien Di Benedetto no ignora el pasado histórico, ha sido leído mayoritariamente desde una clave alegórica, simbólica e incluso metafísica. Sin embargo, Martel ha acentuado la lectura histórica a partir de un problema que fue decisivo en la construcción de la sociedad americana: la «cuestión criolla». La organización de la trama, la elección y omisión de episodios, obedecen, como creo haberlo mostrado, a la necesidad de explicitar su propuesta de lectura centrada en la situación de postergación del criollo en la estructura del poder colonial pocos años antes de las guerras independentistas. Y Martel lo ha hecho desplegando un lenguaje visual que, en dialogante sintonía con la novela, enfatiza justamente en esa resistencia del criollo a aceptarse como tal y a renunciar a su deseo de ser considerado y tratado como un español. Al construir un personaje que acaba aceptando su condición y rechazando los modelos de las cortes instaladas en América que imitan patéticamente a la metrópoli, la «cuestión criolla» explicitada en la situación laboral de Diego de Zama, así como en su relación con las mujeres, es el eje en torno al que gira la propuesta de adaptación de Martel.

\section{BibliografíA}

Anónimo, «En Zama "hay una necesidad de demencia para pertenecer a la sociedad"», Diario Uno, 25 de septiembre de 2017, <https://www. diariouno.com.ar/ espectaculos/en-zama-hay-una-necesidad-de-demencia-para-pertenecera-la-sociedad--09252017_Bkgnd9PG0G>.

Anónimo, «Zama atrapado en la esperanza», El País, 7 de octubre de 2017, <https:// elpais.com/cultura/2017/10/07/actualidad/1507401583_261239.html>.

Basualdo, Gonzalo, «Zama: hombre de ningún lugar, o la tradición en construcción», Hologramática Literaria, 3.2, 2006-2007, pp. 127-138.

Borges, Jorge Luis, «El escritor argentino y la tradición», en Discusión. Obras completas (1923-1972), Buenos Aires, Emecé editores, 1987, pp. 267-274.

Cañedo-Argüelles Fábrega, Teresa, La provincia de Corrientes en los siglos XVI y XVII: un modelo de colonización en el Alto Paraná, Madrid, CSIC (Centro de Estudios Históricos-Departamento de Historia de América), 1988.

Del Vecchio, Alejandro, «Dibujados con un pincel finísimo de pelo de camello: el caso Zama, de Antonio Di Benedetto», Espéculo, 39, 2008, s. p. Disponible en < https://webs.ucm.es/info/especulo/numero39/casozama.htmls.

Di Benedetto, Antonio, «Autobiografía», en Páginas de Antonio Di Benedetto seleccionadas por el autor, Buenos Aires, Celtia, 1987, pp. 251-252.

Di Benedetto, Antonio, Zama, Buenos Aires, Adriana Hidalgo editora, 2013 [1956].

Genette, Gerard, Palimpsestos: Ia literatura en segundo grado, Madrid, Taurus, 1989. 
Hoberman, James Lewis, «Lucrecia Martel, una directora que desconcierta y estremece a sus seguidores», The New York Times, 13 de abril de 2018, < https:// www.nytimes.com/2018/04/13/movies/lucrecia-martel-zama-argentina. html>.

Koza, Roger, «El cine espiritualizado», Con los ojos abiertos, 2017. Disponible en <http://www.conlosojosabiertos.com/19493-2/>.

Lavallé, Bernard, «Espacio y reivindicación criolla», en Las promesas ambiguas. Ensayos sobre el criollismo colonial en los Andes, Lima, Fondo Editorial Pontificia Universidad Católica del Perú/Instituto Riva Agüero, 1993, pp. 105-127.

Legaz, María Elena, «Tres metáforas de lo heroico», en Actas del Congreso Nacional de Literatura Argentina, Córdoba, Universidad Nacional de Córdoba, Facultad de Humanidades, 1991, s. p.

Lorenz, Günter, Diálogo con Latinoamérica, Valparaíso, Pomaire, 1972.

Martel, Lucrecia (Directora), Zama, Daniel Giménez Cacho, Matheus Nachtergale, Juan Minujin, Lola Dueñas, Rafael Spregelburd, Coproducción ArgentinaEspaña-Francia-México-Brasil-Estados Unidos-Países Bajos (Holanda), Rei Cine/El Deseo/Canana Films/KNM/Bananeira Filmes/Louverture Films/ Netherland Filmfund/INCAA, 2016.

Mazzotti, José Antonio, Lima fundida. Épica y nación criolla en el Perú, Madrid/ Frankfurt am Main, Iberoamericana/Vervuert, 2016.

Nállim, Carlos Orlando, «Zama: entre texto, estilo e historia», Anales de Literatura Hispanoamericana, 1, 1972, pp. 337-358.

Néspolo, Jimena, «Antonio Di Benedetto, el escritor anti-boom», Babelia, 1 de abril, 2017, n. 1323.

Pécora, Pablo, «Lucrecia Martel: hay una necesidad de demencia para pertenecer a la sociedad», La Capital de Mar de Plata, 25 de septiembre de 2017, <https:// www.lacapitalmdp.com/lucrecia-martel-hay-una-necesidad-de-demenciapara-pertenecer-a-la-sociedad/>.

Rodríguez Garrido, José Antonio, «Lorenzo de las Llamosas y el pensamiento crioIlo en el Perú a fines del XVII», en La formación de la cultura virreinal, Tomo II: El siglo XVII, ed. Karl Kohut y Sonia V. Rose, Madrid/ Frankfurt am Main, Iberoamericana /Vervuert, 2004, pp. 456-472.

Saer, Juan José, «Prólogo», en Antonio Di Benedetto, Trilogía, Zama, El silenciero, Los suicidas, Las novelas de la espera, Buenos Aires, Adriana Hidalgo editora, 2018, pp. 7-11.

Saer, Juan José, «Contratapa», en Antonio Di Benedetto, Zama, Buenos Aires, Adriana Hidalgo editora, 2013.

Stam, Robert, «Beyond Fidelity: The Dialogics of Adaptation», en Film Adaptation, ed. James Naremore, New Bruswick, Rutgers University Press, 2000, pp. 54-76. 
Tenebras Lux, «Zama de Antonio di Benedetto no es Zama de Lucrecia Martel», Kunst, 5 de octubre de 2017, <https://revistakunst.com/2017/10/05/zamade-antonio-di-benedetto-no-es-zama-de-lucrecia-martel/s.

Vinatea, Martina, «Estudio preliminar», en Fundación y grandezas de la muy noble y muy leal ciudad de los Reyes de Lima de Rodrigo de Valdés, ed. Martina Vinatea, New York, Instituto de Estudios Auriseculares (IDEA), 2018, pp. 15-124. 